\title{
Dyad synthesis of planar seven-link variable topology mechanism for motion between two dead-centre positions
}

\author{
Gururaj M Gadad $^{1}$, H V Ramakrishan ${ }^{2}$ M S Srinath ${ }^{3}$, S S Balli ${ }^{4}$ \\ ${ }^{1}$ (Department of Mechanical Engineering,SDM College of Engineering \& Technology, Dharwad, India) \\ ${ }^{2,3}$ (Department of Mechanical Engineering, Malnad Engineering College, Hasan, India) \\ ${ }^{4}$ (Department of Mechanical Engineering, Basaveshwar Engineering College Bagalkot)
}

\begin{abstract}
This paper suggests variable topology method using Dyad technique for synthesizing seven-link planar mechanism for motion between two dead centre positions. The tasks like path generation with prescribed timing and function generation are also dealt with. Numerical examples are provided and are verified. Complex numbers, which readily lend themselves as an ideal tool for modeling linkage members as parts of planar mechanisms, are used for writing displacement equations for dyads.
\end{abstract}

Keywords - Dyad synthesis, Dead centers Seven-link mechanism, Variable topology,

\section{INTRODUCTION}

A seven-link mechanism has two degrees of freedom. There are many methods proposed for synthesizing such a mechanism. A seven-bar linkage with variable topology operates in two phases. In each phase, a link adjacent to the permanently fixed link of seven-bar linkage is also fixed temporarily and the resulting portion acts like a six-bar mechanism with single degree of freedom [1].

To begin with an overview of the variable topology mechanism is given to form the basis of the method developed in the present work. Rose [2], Ting and Tsai [3] and Ting [4] made indirect reference of fivebar variable topology mechanism with the help of graphical methods. Rawat [5] established a synthesis technique for five-bar topology mechanism operating in two phases. Joshi et.al.[6] and Joshi [7] used the dyad synthesis of a five-bar topology mechanism for circuit breaker applications. Balli and Chand [1] deal with various aspects like transmission angle control defects and solutions rectification of five-bar variable topology mechanism. Chand and Balli [1] proposed a method of synthesis of a seven-link mechanism with variable topology.

Among the many factors to be considered for the effective force / motion transmission by a mechanism, the transmission angle is one of the important criteria. The control of transmission angle with in some reasonable range is attempted. A variable topology synthesis method is suggested as an alternative to the multi-loop synthesis method suggested by Sandor and Erdman. Many multi-loop mechanisms can be synthesized by repeated use of the same standard form solution method by employing compatibility equations [8]. Triad synthesis suggested by Lin and Erdman involves writing and solving compatibility equations by iterative calculations. The suggested method of variable topology reduces the cumbersome calculations.

\section{VARIABLE TOPOLOGY OF SEVEN-LiNKS MECHANISM}

Any mechanism with five or more links and with two or more degrees of freedom can be made to acts as variable topology mechanism operating in two or more phases [1]. The vector representation of planar sevenlinks mechanism is shown in Fig.2.1. Figures 2.2 (a) and 2.2(b) show Phase-I and Phase-II respectively and are discussed in the following paragraphs;

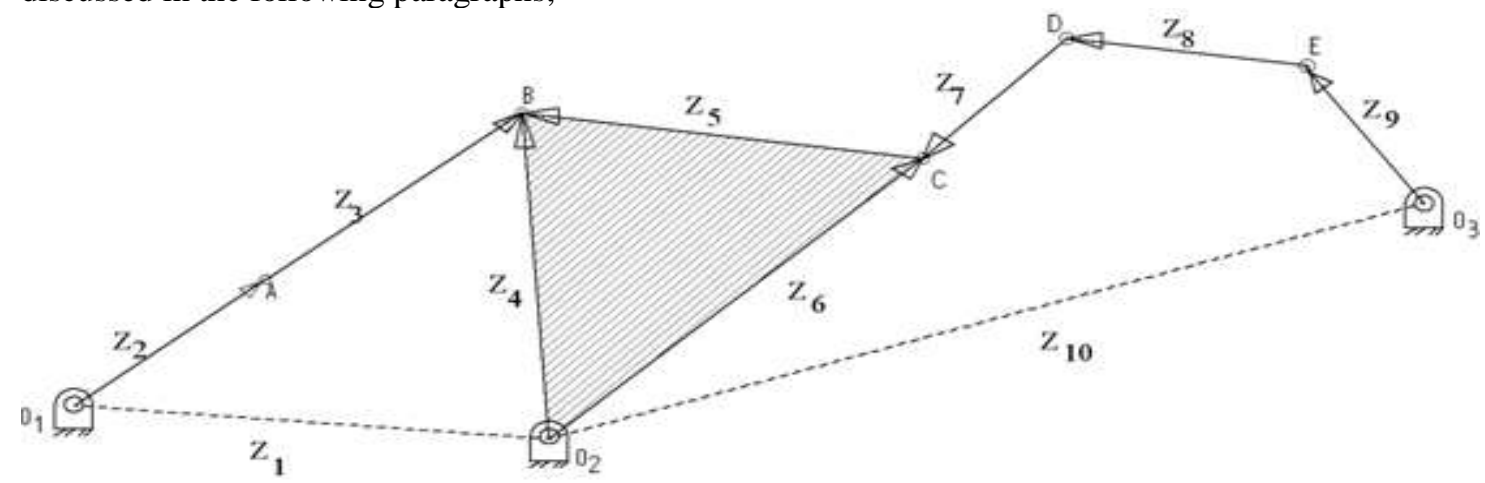

Fig. 2.1. A vector representation of planar seven-link two-DOF mechanism Table 2.1 Convention followed to denote the angles in phase-I and Phase-II 
Dyad synthesis of planar seven-link variable topology mechanism for motion between two dead-

\begin{tabular}{|c|c|c|}
\hline $\begin{array}{c}\text { Link, Vector } \\
\text { representation \& angle } \\
\text { between two different } \\
\text { position of link }\end{array}$ & $\begin{array}{c}\text { Prom } 1^{\text {st }} \\
\text { position to } 2^{\text {nd }} \\
\text { position } \\
\text { Suffix }-1\end{array}$ & $\begin{array}{c}\text { Phase - II } \\
\text { From } 2^{\text {nd }} \text { position to } 3^{\text {rd }} \\
\text { position } \\
\text { Suffix - } 2\end{array}$ \\
\hline $\mathrm{O}_{1} \mathrm{~A}-\mathrm{Z}_{2}-\varphi$ & $\varphi_{1}$ & Temporarily fixed \\
\hline $\mathrm{AB}-\mathrm{Z}_{3}-\alpha$ & $\alpha_{1}$ & $\alpha_{2}$ \\
\hline $\mathrm{BC}-\mathrm{Z}_{5}-\Psi$ & $\Psi_{1}$ & $\Psi_{2}$ \\
\hline $\mathrm{O}_{2} \mathrm{~B}-\mathrm{Z}_{4}-\Psi$ & $\Psi_{1}$ & $\Psi_{2}$ \\
\hline $\mathrm{O}_{2} \mathrm{C}-\mathrm{Z}_{6}-\Psi$ & $\Psi_{1}$ & $\Psi_{2}$ \\
\hline $\mathrm{CD}-\mathrm{Z}_{7}-\beta$ & $\beta_{1}$ & $\mathrm{~B}_{2}$ \\
\hline $\mathrm{DE}-\mathrm{Z}_{8}-\gamma$ & $\gamma_{1}$ & $\gamma_{2}$ \\
\hline $\mathrm{O}_{3} \mathrm{E}-\mathrm{Z}_{9}-\theta$ & Temporarily fixed & $\Theta$ \\
\hline $\mathrm{O}_{1} \mathrm{O}_{2}-\mathrm{Z}_{1}$ & Fixed Link & Fixed Link \\
\hline $\mathrm{O}_{2} \mathrm{O}_{3}-\mathrm{Z}_{10}$ & Fixed Link & Fixed Link \\
\hline Displacement Vector & $\mathrm{B}_{1} \mathrm{~B}_{2}=\delta_{1}$ & $\mathrm{D}_{2} \mathrm{D}_{3}=\delta_{2}$ \\
\hline Sign convention & $\mathrm{CCW}$ motion $+\mathrm{ve}$ & $\mathrm{CW}$ motion $-\mathrm{ve}$ \\
\hline
\end{tabular}

\subsection{Phase-I}

In the present work a seven-link variable topology mechanism consisting of a ternary link-5 is considered. In Phase-I, the link $\mathrm{E}^{1} \mathrm{O}_{3}$ is temporarily fixed and therefore, linkage becomes a six-bar mechanism with single degree of freedom, a Watt II type Linkage. $\mathrm{O}_{1} \mathrm{~A}$ is the input link; B is the possible tracer point. Suffix 1 and 2 of alphabets in Fig.2.2 (a) show the two finitely separated positions of the six-bar portion of the seven-bar variable topology mechanism in Phase-I. It is to be noted that $\mathrm{E}_{1}$ is a temporarily fixed pivot; $\mathrm{O}_{1}$ and $\mathrm{O}_{2}$ are the permanently fixed pivots.

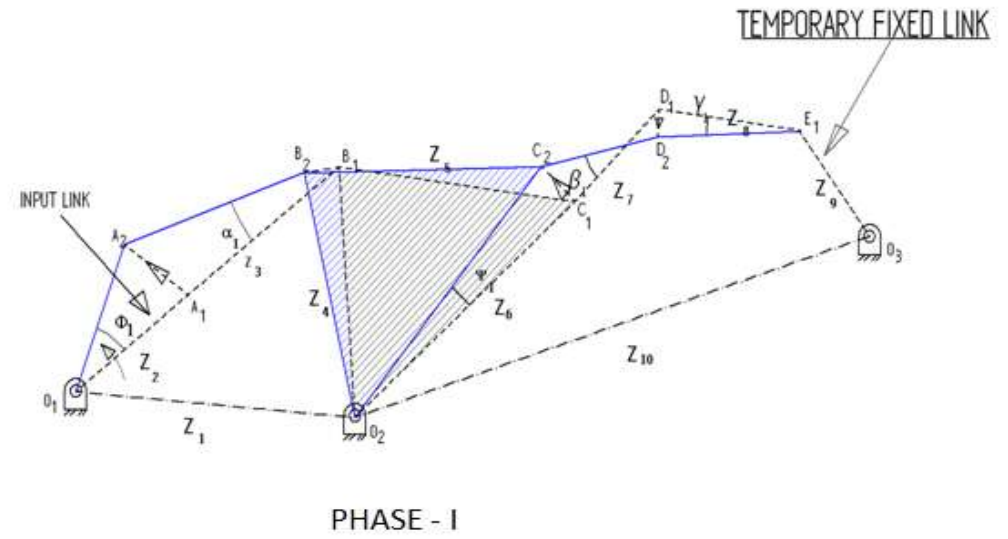

Fig. 2.2(a): A planar seven-link variable topology mechanism for motion between two dead centre positions, Phase-I

\subsection{Phase-II}

Once the above six-bar portion of seven-bar mechanism, reaches the position 2, the link $\mathrm{E}_{1} \mathrm{O}_{3}$ is released to move and the link $\mathrm{O}_{1} \mathrm{~A}$ is fixed temporarily, thus switching on to the Phase-II. In Phase-II also, it is single degree of freedom, six-bar mechanism of Watt II type. Link $\mathrm{E}_{1} \mathrm{O}_{3}$ is the input link; $\mathrm{D}$ is the possible tracer point. Suffix 2 and 3 of alphabets in Fig.2.2 (b) show the two finitely separated positions of the six- bar portion of the seven-link variable topology mechanism in Phase II. It is to be noted that D is no more a fixed pivot whereas $\mathrm{A}_{2}$ is temporarily fixed pivot. $\mathrm{O}_{1}$ and $\mathrm{O}_{2}$ are the permanently fixed pivots. 


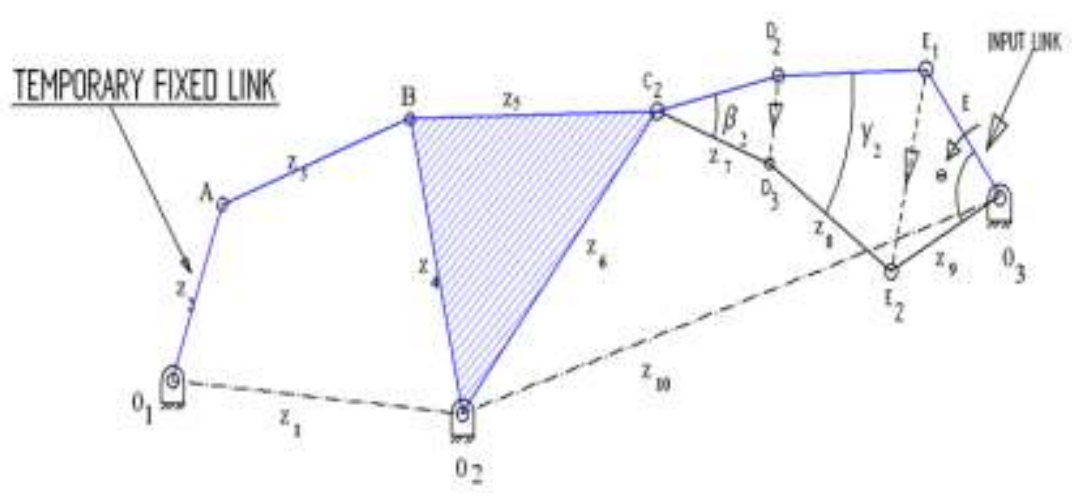

PHASE II

Fig. 2.2(b): A planar seven-link variable topology mechanism for motion between two dead centre positions, Phase-II

\section{Solution Steps}

Following are the existing methods of synthesis of seven link mechanisms in general.

- Dyad synthesis of mechanisms by Sandor and Erdman. [8]

- Triad synthesis by Lin and Sen. [9]

Here we have used the variable topology method [1] . The problem to be solved consists of the following steps:

(i) To identify the link to be fixed temporarily and input link in each phase of operation.

(ii) To recognize the type of mechanism in each Phase (Stephenson, Watt or any other)

(iii) To write done the standard dyad and triad equations for function generation between position 1 and position 2 of Phase I, and also between position 2 and 3 of Phase II.

(iv) To identify the values to be specified, values to be chosen freely and the unknowns based on function generation.

(v) To solve the equations of function generation in each phase separately in phase separately for the link lengths.

(vi) To retain the lengths of Phase I while solving the equations in Phase II.

(vii) To find out the total numbers of solutions all by the method.

\subsection{Types of six-bar linkage and dead-center positions}

From Figs. 2.2 (a) and (b), one can understand that the designer may get different types of six-bar linkage mechanism in different phases depending upon the link fixed temporarily. Yan and Wu discussed the different configurations of six-bar mechanisms in their dead-center positions. According to them Watt-I six-bar linkage has seven dead-center positions, Watt-II six-bar linkage has seven dead-center positions, Stephenson-I six-bar linkage has seven dead-center positions, Stephenson-II six-bar linkage has five dead-center positions and Stephenson-III six-bar linkage has seven dead-center positions. If the six-bar portion of seven-link variable topology mechanism is other than these Watt or Stephenson types, the different dead-center positions are to be identified. Symmetric seven-bar linkage, Type-I and Type-II plane seven-link mechanisms, special configurations like co-axial and the cyclically symmetric mechanisms may also be considered for the variable topology synthesis. These may yield different types of six-bar linkages in two phases after fixing temporarily a link adjacent to permanently fixed link.

Every type of six-bar mechanism has 6 or 7 dead centers. Consider any two dead centre positions. Identify the dyads and synthesize the mechanism after writing standard dyad equation for motion between these two dead centre positions.

It is assumed that the mechanism moves from dead-centre position 1 to the dead centre position 2 in Phase-I and from dead-centre position 2 to the dead-centre position 3 in Phase-II. In the present case, as soon as the mechanism moves from one dead centre position to the other, it stops and then switches on to the Phase-II. So there is no question of overcoming the dead lock and hence, no auxiliary drive is needed

It is required to synthesize a planar seven-link mechanism (shown in Fig. 2.1) with variable topology. One can have two options as follows: 
Dyad synthesis of planar seven-link variable topology mechanism for motion between two dead-

(i) One end link is fixed temporarily,

(ii) Other end link is fixed temporarily

\subsection{Motion Generation (Phase-I Synthesis)}

The input motion in Phase-I is $\varphi_{1}$. The displacement vector $\mathrm{B}_{1} \mathrm{~B}_{2}$ is given by $\delta_{1}$.

Writing the dyad equations for Phase-I (refer Fig. 2.2(a))

$$
\begin{aligned}
& Z_{2}\left(e^{i \theta_{1}}-1\right)+Z_{2}\left(e^{i \alpha_{1}}-1\right)=\delta_{1} \\
& Z_{2}\left(e^{i \Psi_{1}}-1\right)+Z_{7}\left(e^{i \beta_{1}}-1\right)+Z_{5}\left(e^{i \Psi_{1}}-1\right)=\delta_{1} \\
& Z_{4}\left(e^{i \Psi_{1}}-1\right)=\delta_{1}
\end{aligned}
$$

In the standard dyad equation (4.1), (4.2) and (4.3), in case of motion generation, the coupler point motions $\left(\alpha_{1}\right.$ and $\left.\Psi_{1}\right)$ and displacement vector $\left(\delta_{1}\right)$ are prescribed. $\gamma_{1}, \beta_{1}, \varphi_{1}, Z_{2}, Z_{6}$ and $Z_{8}$ are the free choices.

Then unknowns

$Z_{1}, Z_{1}, Z_{4}, Z_{5}, Z_{7}$, and $Z_{11}\left(\mathrm{O}_{3} \mathrm{E}_{1}\right)$ are determined as follows:

Referring Fig. 2.2 (a),

$$
\begin{aligned}
& Z_{3}=\frac{E_{1}-Z_{2}\left(e^{i p=1}-1\right)}{\left(e^{i=1}-1\right)} \\
& \mathrm{Z}_{4}=\frac{\delta_{1}}{\left(\mathrm{e}^{\mathrm{i} \omega 1}-1\right)} \\
& \mathrm{Z}_{7}=\frac{\delta_{1}-\mathrm{Z}_{8}\left(\mathrm{e}^{\mathrm{i} Y 1}-1\right)-\mathrm{Z}_{5}\left(\mathrm{e}^{\mathrm{i} \Psi_{1}}-1\right)}{\left(\mathrm{e}^{\mathrm{i} \beta 1}-1\right)}
\end{aligned}
$$

From loop closure equations,

$$
\begin{aligned}
& Z_{1}=O_{1} O_{2}=Z_{2}+Z_{3}-Z_{4} \\
& Z_{5}=Z_{4}-Z_{6} \\
& Z_{11}=O_{2} E_{1}=Z_{6}-Z_{7}-Z_{8}
\end{aligned}
$$

\subsection{Motion Generation (Phase-II Synthesis)}

The input motion in Phase-II is $\theta$. The displacement vector $\mathrm{D}_{2} \mathrm{D}_{3}$ is given by $\delta_{2}$.

Writing the dyad equations for Phase-II (refer Fig. 2.2(b))

$$
\begin{aligned}
& Z_{9}\left(e^{i \theta_{1}}-1\right)+Z_{8} e^{i \gamma_{1}}\left(e^{i \gamma_{2}}-1\right)=\delta_{2} \\
& Z_{7} e^{i \beta_{1}}\left(e^{i \beta_{2}}-1\right)=\delta_{2}
\end{aligned}
$$

All the link lengths except the link $\mathrm{Z}_{9}, \mathrm{Z}_{10}$ and $\mathrm{Z}_{12}\left(\mathrm{O}_{2} \mathrm{~A}\right)$ are known from Phase-I. Equation (2.10) is solved to determine the $\mathrm{Z}_{9}$ while $\mathrm{Z}_{10}$ and $\mathrm{Z}_{12}\left(\mathrm{O}_{2} \mathrm{~A}\right)$ are determined by loop closure equations.

Here, $\delta_{2}$ and $\gamma_{2}$ are prescribed and $\theta$ is free choice. Then unknowns $Z_{9}, Z_{10}$ and $Z_{12}\left(\mathrm{O}_{2} A\right)$ are determined as follows:

$$
\mathrm{Z}_{9}=\frac{\delta_{2}-\mathrm{Z}_{8} \mathrm{e}^{\mathrm{i} \gamma 1}\left(\mathrm{e}^{\mathrm{i} \gamma 2}-1\right)}{\left(\mathrm{e}^{\mathrm{i} \theta}-1\right)}
$$

From loop closure equations,

$$
\begin{aligned}
& Z_{10}=Z_{9}+Z_{8}-Z_{7}-Z_{6} \\
& Z_{12}=O_{2} A=Z_{3}-Z_{5}-Z_{6}
\end{aligned}
$$

Table 2.2 Summary of Phase-I and II, Synthesis of Seven-Link VTM for two finitely Separated Positions for Motion Generation (Rigid Body Guidance)

\begin{tabular}{|c|c|c|}
\hline Description & Phase-I & Phase-II \\
\hline Link fixed temporarily & $\mathrm{O}_{3} \mathrm{E}$ & $\mathrm{O}_{1} \mathrm{~A}$ \\
\hline Prescribed parameters & $\alpha_{1}, \Psi_{1}$ and $\delta_{1}$ & $\delta_{2}$ and $\gamma_{2}$ \\
\hline Free choice made & $\gamma_{1}, \beta_{1}, \varphi_{1}, \mathrm{Z}_{2}, \mathrm{Z}_{6}$ and $\mathrm{Z}_{8}$ & $\theta$ \\
\hline Unknowns & $\mathrm{Z}_{1}, \mathrm{Z}_{3}, \mathrm{Z}_{4}, \mathrm{Z}_{5}, \mathrm{Z}_{7}$ and $\mathrm{Z}_{11}\left(\mathrm{O}_{2} \mathrm{E} 1\right)$ & $\mathrm{Z}_{9}, \mathrm{Z}_{10}$ and $\mathrm{Z}_{12}\left(\mathrm{O}_{2} \mathrm{~A}\right)$ \\
\hline
\end{tabular}

\subsection{Path Generation with prescribed timing}

By interchanging the values to be prescribed and the values to be free chosen of motion generation problem above, it results in a problem of path generation with prescribed timings. Except this, there is no much difference in the synthesis procedure of seven-link Variable Topology Mechanism for path generation with prescribed timing. 
Dyad synthesis of planar seven-link variable topology mechanism for motion between two dead-

\section{Phase-I synthesis}

The input crank motion $\varphi_{1}, \gamma_{1}, \beta_{1}$ and displacement vector $\left(\delta_{1}\right)$ are prescribed. $\alpha_{1}, \Psi_{1}, Z_{2}, Z_{6}$ and $Z_{8}$ are the free choices. Then the unknowns $\mathrm{Z}_{1}, \mathrm{Z3}, \mathrm{Z}_{4}, \mathrm{Z}_{5}, \mathrm{Z}_{7}$ and $\mathrm{Z}_{11}\left(\mathrm{O}_{2} \mathrm{E}_{1}\right)$ are determined using equations (4.4), (4.5), (4.6), (4.7), (4.8) and (4.9) respectively.

\section{Phase-II synthesis}

Here, $\delta_{2}$ and $\theta$ are prescribed and $\gamma_{2}$ is free choice. Then unknowns $Z_{9}, Z_{10}$ and $Z_{12}\left(O_{2} A\right)$ are determined by using equations (4.12), (4.13) and (4.14) respectively.

Table 2.3 Summary of Phase-I and II, Synthesis of Seven-Link VTM for two finitely Separated Positions for Path Generation with Prescribed Timings:

\begin{tabular}{|c|c|c|}
\hline Description & Phase-I & Phase-II \\
\hline Link fixed temporarily & $\mathrm{O}_{3} \mathrm{E}$ & $\mathrm{O}_{1} \mathrm{~A}$ \\
\hline Prescribed parameters & $\varphi_{1}, \gamma_{1}, \beta_{1}$, and $\delta_{1}$ & $\theta$ and $\delta_{2}$ \\
\hline Free choice made & $\alpha_{1}, \Psi_{1}, Z_{2}, Z_{6}$ and $Z_{8}$ & $\gamma_{2}$ \\
\hline Unknowns & $Z_{1}, Z 3, Z_{4}, Z_{5}, Z_{7 \text { and }} Z_{11}\left(O_{2} E_{1}\right)$ & $\mathrm{Z}_{9}, \mathrm{Z}_{10}$ and $\mathrm{Z}_{12}\left(\mathrm{O}_{2} \mathrm{~A}\right)$ \\
\hline
\end{tabular}

\subsection{Function Generation (Phase-I synthesis)}

In function generation problem, the input and output crank motions $\left(\varphi_{1}, \Psi_{1}\right.$ and $\left.\gamma_{1}\right), Z_{4}$ and $Z_{6}$ are prescribed. $\alpha_{1}, \beta_{1}, Z_{2}$ and $Z_{8}$ are the free choices. Then the unknowns $Z_{1}, Z_{3}, Z_{5}, Z_{7}$ and $Z_{11}\left(O_{2} E_{1}\right)$ are determined as follows:

$$
\begin{aligned}
& Z_{2}\left(e^{i \varphi_{1}}-1\right)+Z_{3}\left(e^{i \alpha_{1}}-1\right)=Z_{4}\left(e^{i \psi_{1}}-1\right) \\
& Z_{8}\left(e^{i \psi_{1}}-1\right)+Z_{7}\left(e^{i \beta_{1}}-1\right)+Z_{5}\left(e^{i \psi_{1}}-1\right)=Z_{4}\left(e^{i \psi_{1}}-1\right) \\
& Z_{4}\left(e^{i \psi_{1}}-1\right)=\delta_{1}
\end{aligned}
$$

Where $\delta_{1}$ is the displacement vector, $\mathrm{B}_{1} \mathrm{~B}_{2}$

Reducing the Eqn. (4.15) and (4.16) to the forms of standard dyad equations as follows:

$$
\begin{aligned}
& Z_{2}\left(e^{i \varphi_{1}}-1\right)+Z_{3}\left(e^{i \alpha_{1}}-1\right)=\delta_{1} \\
& Z_{8}\left(e^{i \psi_{1}}-1\right)+Z_{7}\left(e^{i \beta_{1}}-1\right)+Z_{5}\left(e^{i \psi_{1}}-1\right)=\delta_{1}
\end{aligned}
$$

Where

$$
\begin{aligned}
\mathrm{Z}_{3} & =\frac{\delta_{1}-\mathrm{Z}_{2}\left(\mathrm{e}^{\mathrm{i} \phi 1}-1\right)}{\left(\mathrm{e}^{\mathrm{i} \alpha 1}-1\right)} \\
\mathrm{Z}_{7} & =\frac{\delta_{1}-\mathrm{Z}_{8}\left(\mathrm{e}^{\mathrm{i} Y 1}-1\right)-\mathrm{Z}_{5}\left(\mathrm{e}^{\mathrm{i} \Psi_{1}}-1\right)}{\left(\mathrm{e}^{\mathrm{i} \beta 1}-1\right)}
\end{aligned}
$$

$\mathrm{Z}_{1}, \mathrm{Z}_{5}, \mathrm{Z}_{11}\left(\mathrm{O}_{2} \mathrm{E}_{1}\right)$ are determined using equations (4.7), (4.8) and (4.9) respectively.

\subsection{Function Generation (Phase-II synthesis)}

Writing the loop closure equation for Phase-II (refer Fig 2.2(b))

$$
Z_{9}\left(e^{i \theta_{1}}-1\right)+Z_{8} e^{i \gamma_{1}}\left(e^{i \gamma_{2}}-1\right)=Z_{7} e^{i \beta_{1}}\left(e^{i \beta_{2}}-1\right)
$$

Reducing the Eqn. (4.20) to the forms of standard dyad equations as follows:

Let $Z_{7} e^{i \beta_{1}}\left(e^{i \beta_{2}}-1\right)=\delta_{2}$

$$
Z_{9}\left(e^{i \theta_{1}}-1\right)+Z_{8} e^{i \gamma_{1}}\left(e^{i \gamma_{2}}-1\right)=\delta_{2}
$$

Here, the input and output crank motions ( $\beta_{2}$ and $\theta$ ) are prescribed and $\gamma_{2}$ are free choice. Then unknowns $Z_{9}$, $\mathrm{Z}_{10}$ and $\mathrm{Z}_{12}\left(\mathrm{O}_{2} \mathrm{~A}\right)$ are determined as follows:

$$
\mathrm{Z}_{9}=\frac{\delta_{2}-\mathrm{Z}_{8} \mathrm{e}^{\mathrm{i} \gamma 1}\left(\mathrm{e}^{\mathrm{i} \gamma^{2}-1}\right)}{\left(\mathrm{e}^{\mathrm{i} \theta}-1\right)}
$$

$\mathrm{Z}_{10}$ and $\mathrm{Z}_{12}\left(\mathrm{O}_{2} \mathrm{~A}\right)$ are determined by using Eqns. (4.13) and (4.14) respectively. 
Dyad synthesis of planar seven-link variable topology mechanism for motion between two dead-

Table 2.4 Summary of Phase-I and II, Synthesis of Seven-Link VTM for two Finitely Separated Positions for

Function Generation:

\begin{tabular}{|c|c|c|}
\hline Description & Phase-I & Phase-II \\
\hline Link fixed temporarily & $\mathrm{O}_{3} \mathrm{E}$ & $\mathrm{O}_{1} \mathrm{~A}$ \\
\hline Prescribed parameters & $\varphi_{1}, \Psi_{1}, \gamma_{1}, \mathrm{Z}_{4}$ and $\mathrm{Z}_{6}$ & $\theta$ and $\beta_{2}$ \\
\hline Free choice made & $\alpha_{1}, \beta_{1}, \mathrm{Z}_{2}$ and $\mathrm{Z}_{8}$ & $\gamma_{2}$ \\
\hline Unknowns & $\mathrm{Z}_{1}, \mathrm{Z}_{3}, \mathrm{Z}_{5}, \mathrm{Z}_{7}$ and $\mathrm{Z}_{11}\left(\mathrm{O}_{2} \mathrm{E}_{1}\right)$ & $\mathrm{Z}_{9}, \mathrm{Z}_{10}$ and $\mathrm{Z}_{12}\left(\mathrm{O}_{2} \mathrm{~A}\right)$ \\
\hline
\end{tabular}

IV. Advantages of the method.

Following are the some of the advantages of the method.

- More number of unknown parameters are found in the Phase-I and less calculations are required in PhaseII.

- The solution is consistent with the definitions of standard Kinematics tasks like function generation, path and motion generations for two positions resulting in a unified method of synthesis.

- Simplicity, ease of application and generality are the attractions of the method.

- Unlike graphical methods, it is not limited by drawing accuracy.

\section{Limitations of the method}

- The proposed method is applicable only to complex number approach and solution by variable topology method.

- The mechanism synthesized by the method may suffer from branch, Grashof or circuit defects, which can be rectified separately.

- The solution does not permit good initial guesses for all possible solutions i.e free choices.

- Solution method is applicable to some of the seven-bar variable topology mechanisms.

\section{Conclusion}

This present work suggests variable topology method using Dyad and Triad techniques for synthesizing seven-bar planar mechanisms. An analytical method for synthesizing seven-links mechanism with variable topology for two positions is suggested for function generation. Complex numbers, which readily lend themselves as an ideal tool for modeling linkage members as parts of planar mechanisms, are used for writing displacement equations for dyads and triads. The method is suggested as an alternative to the multi-loop synthesis method and triad synthesis which involves writing and solving compatibility equations by iterative calculations.

\section{Numerical example}

(seven-bar variable topology mechanisms acting as Watt II type six-bar mechanism in Phase I and

Phase II.)

Problem: It is required to synthesize a seven-link mechanism with variable topology for the motion between the dead centre positions for the following tracer point displacement specifications:

Phase-I: From point $(55.260,42.971)$ to the point $(47.950,41.890)$.

Phase-II: From point $(122.13,48.75)$ to the point $(120.39,34.74)$.

Suggest the dimensions of the mechanism for

(a) Motion Generation,

(b) Path Generation with prescribed timings and

(c) Function Generation.

Solution: (a)Motion Generation:

\section{Phase-I Synthesis:}

Given that: Prescribed parameter

Displacement, $\delta_{1}=(47.950+41.890 \mathrm{i})-(55.260+42.971 \mathrm{i})=-7.310-1.081 \mathrm{i}$

$\alpha_{1}=18^{0}(\mathrm{cw}), \Psi_{1}=9^{0}(\mathrm{ccw})$

Free Choice

$\gamma_{1}=8^{0}(\mathrm{ccw}), \quad \beta_{1}=32^{0}(\mathrm{cw}), \quad \varphi_{1}=32^{0}(\mathrm{ccw})$

$\mathrm{Z}_{2}=23.59+18.53 \mathrm{i}$

$\mathrm{Z}_{6}=45.94+41.31 \mathrm{i}$

$\mathrm{Z}_{8}=-29.44+4.22 \mathrm{i}$

(Note: CCW motion - +ve and CW motion - - ve) 
Dyad synthesis of planar seven-link variable topology mechanism for motion between two dead-

Unknowns: $\mathrm{Z}_{1}, \mathrm{Z}_{3}, \mathrm{Z}_{4}, \mathrm{Z}_{5}, \mathrm{Z}_{7}$ and $\mathrm{Z}_{11}\left(\mathrm{O}_{2} \mathrm{E}_{1}\right)$

Now, From eqn. (4.4), $\quad Z_{3}=\frac{(-7.310-1.081 i)-(23.59+18.53 i)\left(e^{i 32}-1\right)}{\left(e^{i 18}-1\right)}$

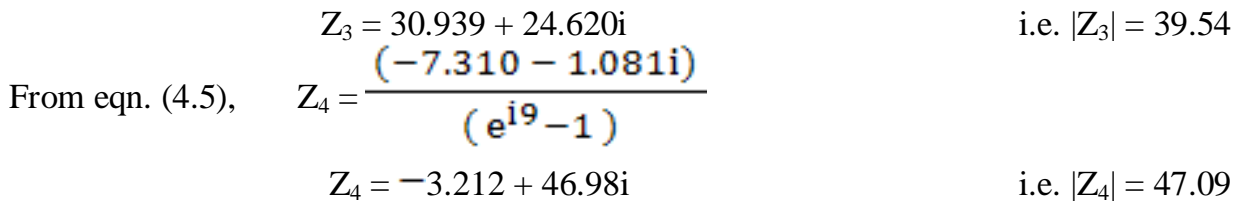

From eqn. (4.6),

$$
\begin{gathered}
\mathrm{Z}_{7}=\frac{(-7.310-1.081 \mathrm{i})-(-29.44+4.22 \mathrm{i})\left(\mathrm{e}^{\mathrm{i} 8}-1\right)-(-49.152+5.67 \mathrm{i})\left(\mathrm{e}^{\mathrm{i} 9}-1\right)}{\left(\mathrm{e}^{\mathrm{i}(-32)}-1\right)} \\
\mathrm{Z}_{7}=-15.1973-18.1877 \mathrm{i} \quad \text { i.e. }\left|\mathrm{Z}_{7}\right|=23.70
\end{gathered}
$$

From eqn. $(4.7), \quad Z_{1}=(23.59+18.53 i)+(30.939+24.620 i)-(-3.212+46.98 i)$

$$
\mathrm{Z}_{1}=57.741-3.83 \mathrm{i} \quad \text { i.e. }\left|\mathrm{Z}_{1}\right|=57.86
$$

From eqn. (4.8), $Z_{5}=Z_{4}-Z_{6}=(-3.212+46.98 i)-(45.94+41.31 i)$

From eqn. (4.9), $Z_{11}=Z_{6}-Z_{7}-Z_{8}$

$$
Z_{5}=-49.152+5.67 \mathrm{i} \quad \text { i.e. }\left|Z_{5}\right|=49.48
$$

$$
\begin{array}{cc}
=(45.94+41.31 \mathrm{i})-(-15.1973-18.1877 \mathrm{i})-(-29.44+4.22 \mathrm{i}) \\
\mathrm{Z}_{11}=90.577+55.278 \mathrm{i} & \text { i.e. }\left|\mathrm{Z}_{11}\right|=106.11
\end{array}
$$

\section{Phase-II Synthesis:}

Given that: Prescribed parameter

Displacement, $\delta_{2}=(120.39+34.74 \mathrm{i})-(122.13+48.75 \mathrm{i})=-1.74-14.01 \mathrm{i}$

$\gamma_{2}=37^{0}(\mathrm{cw})$

Free choice, $\theta=83^{\circ}(\mathrm{ccw})$

(Note: CCW motion - +ve and CW motion - - ve)

Unknowns: $\mathrm{Z}_{9}, \mathrm{Z}_{10}$ and $\mathrm{Z}_{12}\left(\mathrm{O}_{2} \mathrm{~A}\right)$

Now, From eqn. (4.12),

$$
\begin{aligned}
& Z_{9}=\frac{(-1.74-14.01 i)-(-29.44+4.22 i) \mathrm{e}^{\mathrm{i} 8}\left(\mathrm{e}^{\mathrm{i}(-37)}-1\right)}{\left(\mathrm{e}^{\mathrm{i} 83}-1\right)} \\
& Z_{9}=-16.140+18.779 \mathrm{i} \quad \text { i.e. }\left|\mathrm{Z}_{9}\right|=24.76
\end{aligned}
$$

From eqn. (4.13), $\quad Z_{10}=Z_{9}+Z_{8}-Z_{7}-Z_{6}$

$$
\begin{aligned}
& =(-16.140+18.779 \mathrm{i})+(-29.44+4.22 \mathrm{i})-(-15.1973-18.1877 \mathrm{i}) \\
& -(45.94+41.31 \mathrm{i}) \\
& \mathrm{Z}_{10}=106.72+36.50 \mathrm{i} \\
& \text { i.e. }\left|Z_{10}\right|=112.78
\end{aligned}
$$

From eqn. (4.14), $\quad Z_{12}=Z_{3}+Z_{5}-Z_{6}$

$$
\begin{aligned}
& =(30.939+24.620 \mathrm{i})+(-49.152+5.67 \mathrm{i})-(45.94+41.31 \mathrm{i}) \\
& \mathrm{Z}_{12}=-49.04+32.00 \mathrm{i} \quad \text { i.e. }\left|\mathrm{Z}_{12}\right|=58.86
\end{aligned}
$$

(a) Path Generation With Prescribed Timings:

By interchanging the values to be prescribed and the values to be free chosen of motion generation problem above, it results in a problem of path generation with prescribed timings. So, the link length will be same as motion generation which we got in above problem.

(b) Function Generation:

Phase-I Synthesis:

Given that:

$\varphi_{1}=32^{0}(\mathrm{ccw}), \quad \Psi_{1}=9^{0}(\mathrm{ccw}), \gamma_{1}=8^{0}(\mathrm{ccw})$

$\mathrm{Z}_{4}=-3.212+47.80 \mathrm{i}, \quad \mathrm{Z}_{6}=45.94+41.31 \mathrm{i}$

Let, $\alpha_{1}=18^{0}(\mathrm{cw}), \beta_{1}=32^{0}(\mathrm{cw})$

$\mathrm{Z}_{2}=23.59+18.53 \mathrm{i}, \quad \mathrm{Z}_{8}=-29.44+4.22 \mathrm{i}$

Unknowns: $\mathrm{Z}_{1}, \mathrm{Z}_{3}, \mathrm{Z}_{5}, \mathrm{Z}_{7}$ and $\mathrm{Z}_{11}\left(\mathrm{O}_{2} \mathrm{E}_{1}\right)$

Now, From eqn. (4.17), $\quad \delta_{1}=(-3.212+47.80 \mathrm{i})\left(\mathrm{e}^{\mathrm{i} 9}-1\right)$

$$
\delta_{1}=-7.438-1.091 \mathrm{i} \quad \text { i.e. }\left|\delta_{1}\right|=7.52
$$


Dyad synthesis of planar seven-link variable topology mechanism for motion between two dead-

From eqn. (4.20), $\quad \mathrm{Z}_{3}=\frac{(-7.438-1.091 \mathrm{i})-(23.59+18.53 \mathrm{i})\left(\mathrm{e}^{\mathrm{i} 32}-1\right)}{\left(\mathrm{e}^{\mathrm{i}(-18)}-1\right)}$

From eqn. (4.21),

$$
\mathrm{Z}_{3}=31.03+24.22 \mathrm{i} \quad \text { i.e. }\left|\mathrm{Z}_{3}\right|=39.36
$$

$$
\begin{gathered}
Z_{7}=\frac{(-7.438-1.091 i)-(-29.44+4.22 i)\left(\mathrm{e}^{\mathrm{i} 8}-1\right)-(-49.152+6.49 \mathrm{i})\left(\mathrm{e}^{\mathrm{i} 9}-1\right)}{\left(\mathrm{e}^{\mathrm{i}(32)}-1\right)} \\
\mathrm{Z}_{7}=-15.495-17.139 \mathrm{i} \quad \text { i.e. }\left|\mathrm{Z}_{7}\right|=23.15
\end{gathered}
$$

From eqn. (4.7), $\quad Z_{1}=Z_{2}+Z_{3}-Z_{4}$

$$
\begin{gathered}
=(23.59+18.53 \mathrm{i})+(31.03+24.22 \mathrm{i})-(-3.212+47.80 \mathrm{i}) \\
\mathrm{Z}_{1}=57.832-5.05 \mathrm{i} \\
\text { i.e. }\left|\mathrm{Z}_{1}\right|=58.05
\end{gathered}
$$

From eqn. (4.8), $\quad Z_{5}=Z_{4}-Z_{6}=(-3.212+47.80 i)-(45.94+41.31 i)$

$$
Z_{5}=-49.152+6.49 \mathrm{i} \quad \text { i.e. }\left|Z_{5}\right|=49.57
$$

From eqn. (4.9), $\quad Z_{11}=Z_{6}-Z_{7}-Z_{8}$

$$
=(45.94+41.31 \mathrm{i})-(-15.495-17.139 \mathrm{i})-(-29.44+4.22 \mathrm{i})
$$

$$
\mathrm{Z}_{11}=90.875+54.23 \mathrm{i} \quad \text { i.e. }\left|\mathrm{Z}_{11}\right|=105.82
$$

\section{Phase-II Synthesis:}

Given that: Prescribed parameter

$\theta=83^{\circ}(\mathrm{ccw}), \beta_{2}=33^{0}(\mathrm{cw})$

Free choice, $\gamma_{2}=37^{\circ}(\mathrm{cw})$

(Note: CCW motion - +ve and CW motion - - ve)

Unknowns: $\mathrm{Z}_{9}, \mathrm{Z}_{10}$ and $\mathrm{Z}_{12}\left(\mathrm{O}_{2} \mathrm{~A}\right)$

Now,

From eqn. $(4.23), \quad \delta_{2}=(-15.495-17.139 \mathrm{i}) \mathrm{e}^{\mathrm{i}(-32)}\left(\mathrm{e}^{\mathrm{i}(-33)}-1\right)$

$$
\delta_{2}=-0.1412-13.123 \mathrm{i} \quad \text { i.e. }\left|\delta_{2}\right|=13.12
$$

From eqn. (4.25), $\quad Z_{9}=\frac{(-0.1412-13.123 \mathrm{i})-(-29.44+4.22 \mathrm{i}) \mathrm{e}^{\mathrm{i8}}\left(\mathrm{e}^{\mathrm{i}(-37)}-1\right)}{\left(\mathrm{e}^{\mathrm{i} 83}-1\right)}$

From eqn. (4.13), $\quad Z_{10}=Z_{9}+Z_{8}-Z_{7}-Z_{6}$

$$
Z_{9}=-14.443+18.984 i \quad \text { i.e. }\left|Z_{9}\right|=23.85
$$

$$
\begin{array}{rr}
=(-14.443+18.984 \mathrm{i})+(-29.44+4.22 \mathrm{i})-(-15.495-17.139 \mathrm{i})-(45.94+41.31 \mathrm{i}) \\
\mathrm{Z}_{10}=106.72+36.50 \mathrm{i} & \text { i.e. }\left|\mathrm{Z}_{10}\right|=112.78
\end{array}
$$

From eqn. (4.14), $\quad Z_{12}=Z_{3}+Z_{5}-Z_{6}$

$$
=(31.03+24.22 \mathrm{i})+(-49.152+6.49 \mathrm{i})-(45.94+41.31 \mathrm{i})
$$

$$
\mathrm{Z}_{12}=-49.04+32.00 \mathrm{i} \quad \text { i.e. }\left|\mathrm{Z}_{12}\right|=58.86
$$

VIII. Results:

(All values are in $\mathrm{cm}$ )

\begin{tabular}{|l|l|}
\hline 1. MOTION GENERATION & $\left|\mathrm{Z}_{1}\right|=57.86$ \\
\hline $\mathrm{Z}_{1}=57.741-3.83 \mathrm{i}$ & $\left|\mathrm{Z}_{2}\right|=30$ \\
\hline $\mathrm{Z}_{2}=23.59+18.53 \mathrm{i}$ & $\left|\mathrm{Z}_{3}\right|=39.54$ \\
\hline $\mathrm{Z}_{3}=30.939+24.620 \mathrm{i}$ & $\left|\mathrm{Z}_{4}\right|=47.09$ \\
\hline $\mathrm{Z}_{4}=-3.212+46.98 \mathrm{i}$ & $\left|\mathrm{Z}_{5}\right|=49.48$ \\
\hline $\mathrm{Z}_{5}=-49.152+5.67 \mathrm{i}$ & $\left|\mathrm{Z}_{6}\right|=61.78$ \\
\hline $\mathrm{Z}_{6}=45.94+41.31 \mathrm{i}$ & $\left|\mathrm{Z}_{7}\right|=23.70$ \\
\hline $\mathrm{Z}_{7}=-15.1973-18.1877 \mathrm{i}$ & $\left|\mathrm{Z}_{8}\right|=29.74$ \\
\hline $\mathrm{Z}_{8}=-29.44+4.22 \mathrm{i}$ & $\left|\mathrm{Z}_{9}\right|=24.76$ \\
\hline $\mathrm{Z}_{9}=-16.140+18.779 \mathrm{i}$ & $\left|\mathrm{Z}_{10}\right|=112.78$ \\
\hline $\mathrm{Z}_{10}=106.72+36.50 \mathrm{i}$ & $\left|\mathrm{Z}_{11}\right|=106.11$ \\
\hline $\mathrm{Z}_{11}\left(\mathrm{O}_{2} \mathrm{E}_{1}\right)=90.577+55.278 \mathrm{i}$ & $\left|\mathrm{Z}_{12}\right|=58.86$ \\
\hline $\mathrm{Z}_{12}\left(\mathrm{O}_{2} \mathrm{~A}\right)=-49.04+32.00 \mathrm{i}$ & \\
\hline 2. FUNCTION GENERATION & \\
\hline
\end{tabular}


Dyad synthesis of planar seven-link variable topology mechanism for motion between two dead-

\begin{tabular}{|l|l|}
\hline$Z_{1}=57.832-5.05 i$ & $\left|Z_{1}\right|=58.05$ \\
\hline$Z_{2}=23.59+18.53 i$ & $\left|Z_{2}\right|=30$ \\
\hline$Z_{3}=31.03+24.22 i$ & $\left|Z_{3}\right|=39.36$ \\
\hline$Z_{4}=-3.212+47.80 i$ & $\left|Z_{4}\right|=47.91$ \\
\hline$Z_{5}=-49.152+6.49 i$ & $\left|Z_{5}\right|=49.57$ \\
\hline$Z_{6}=45.94+41.31 i$ & $\left|Z_{6}\right|=61.78$ \\
\hline$Z_{7}=-15.495-17.139 i$ & $\left|Z_{7}\right|=23.15$ \\
\hline$Z_{8}=-29.44+4.22 i$ & $\left|Z_{8}\right|=29.74$ \\
\hline$Z_{9}=-14.443+18.984 i$ & $\left|Z_{9}\right|=23.85$ \\
\hline$Z_{10}=106.72+36.50 i$ & $\left|Z_{10}\right|=112.78$ \\
\hline$Z_{11}\left(O_{2} E_{1}\right)=90.875+54.23 i$ & $\left|Z_{11}\right|=105.82$ \\
\hline$Z_{12}\left(O_{2} A\right)=-49.04+32.00 i$ & $\left|Z_{12}\right|=58.86$ \\
\hline
\end{tabular}

References:

[1] Shrinivas S Balli and Satish Chand, "Synthesis of a Planar Seven Link Mechanism with Variable Topology for Motion Between Two Dead Center Positions", Mechanism and Machine Theory, March 2003, pp1271-1287.

[2] Rose, Five-bar loop synthesis, Machine Design, October 1961, pp189-195.

[3] L. Ting, G.H. Tsi, 1985, Mobility and synthesis of five bar programmable linkages, in: Proceedings of $9^{\text {th }}$ OSU Applied Mechanisms Conference, Kansas City, MD, pp. III-1-III-8.

[4] L.Ting, , Five bar Grashof's Criteria, Transactions of ASME, Journal of Mechanisms, Transmission and Automation in Design , 1986 pp 533-537.

[5] Yogesh R Rawat., Synthesis of Variable Topology Mechanisms Graphical Method, M Tech Thesis, 1997, I.I T.Bombay.

[6] Joshi, C. Amaranath.,Y.R. Rawat, Synthesis of Variable Topology Mechanisms for Circuit Breaker Applications, Proceedings of the $8^{\text {th }}$ NaCoMM Conference, 1997, IIT, Kanpur,.

[7] Joshi, S.A, Synthesis of Variable Topology Mechanisms for Circuit Breaker Applications, 1998, M.Tech dissertation,,M.E.D.IIT, Bombay.

[8] A.G.Erdman, G.N.Sandor, Mechanism Design: Analysis and Synthesis, Vol-lI, (Englewood Cliffs, NJ: Prentice-Hall ,1997)

[9] Chuen-Sen Lin and Arthur G Erdman, , Dimensional Synthesis of Planar Triads: Motion Generation with Prescribed Timing for Six Precision Positions" Mechanism and Machine Theory. vol22, No.5. 1987, pp 411-419

[10] Shrinivas S Balli and Satish Chand, "Transmission angle in Mechanisms (Triangle in Mechanism)", Mechanism \& Machine Theory, 2002, 37, ,pp175-195.

[11] Shrinivas S Balli and Satish Chand, December 2000, "Synthesis of Five Bar Mechanism with Variable Topology for Motion Between Extreme positions (SYNFBVTM)”, Mechanisms and Machine Theory,2000,pp 1147-1156.

[12] Shrinivas S Balli and Satish Chand, "Five Bar Motion and Path generators with Variable Topology for Motion Between extreme positions with prescribed timings", Mechanism and Machine Theory, pp1435-1445.

[13] Shrinivas S Balli and Satish Chand, 2002, "Defects in Mechanisms and Solution Rectification, Mechanism" and Machine Theory, 2002, 37, 851-876pp.

[14] S Balli and S Chand, Order Rectification of five bar variable topology mechanism, in Proceedings of the NaCoMM 2001 Conference, December 2001, IIT, Kharagpur, pp.73-80

[15] Shrinivas S Balli and Satish Chand, "Transmission angle in Mechanisms A review, Mechanism and Machine Theory, 2002,37 (2) pp 175-195.

[16] A.H Soni, Mechanism Synthesis and Analysis, McGraw Hill, New York, 1974

[17] T. S. Mrutyunjaya, 1975, A Note on synthesis of the general, two degree of freedom linkage, Mechanism and Machine Theory ,1975, pp 77-80.

[18] A.S.Hall, Kinematics and Linkage Design, Prentice Hall,1961

[19] A.G Erdman, Three and Four precision point Kinematic synthesis of planar linkages, Mechanism and Machine Theory 16, 1981 , pp227-245. 